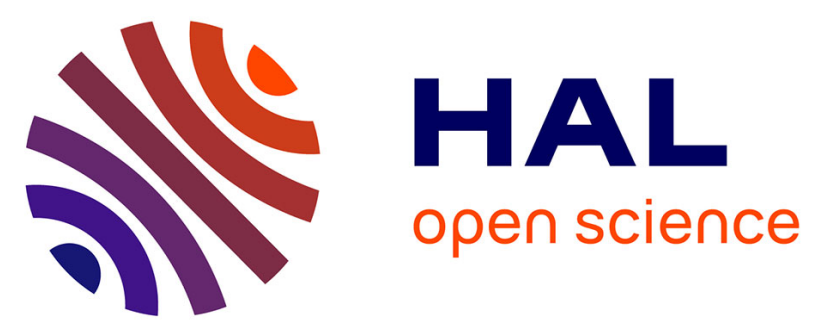

\title{
Colloidal samarium oxide nanoparticles prepared by femtosecond laser ablation and fragmentation for nuclear nanomedicine
}

E. Popova-Kuznetsova, G. Tikhonowski, A. A. Popov, V. R. Duflot, S. M. Deyev, S. M. Klimentov, I. N. Zavestovskaya, P. N. Prasad, A. V. Kabashin

\section{To cite this version:}

E. Popova-Kuznetsova, G. Tikhonowski, A. A. Popov, V. R. Duflot, S. M. Deyev, et al.. Colloidal samarium oxide nanoparticles prepared by femtosecond laser ablation and fragmentation for nuclear nanomedicine. SPIE LASE, Feb 2020, San Francisco, United States. pp.3, 10.1117/12.2551432 . hal-03100452

\section{HAL Id: hal-03100452 \\ https://hal.science/hal-03100452}

Submitted on 6 Jan 2021

HAL is a multi-disciplinary open access archive for the deposit and dissemination of scientific research documents, whether they are published or not. The documents may come from teaching and research institutions in France or abroad, or from public or private research centers.
L'archive ouverte pluridisciplinaire HAL, est destinée au dépôt et à la diffusion de documents scientifiques de niveau recherche, publiés ou non, émanant des établissements d'enseignement et de recherche français ou étrangers, des laboratoires publics ou privés. 


\title{
Colloidal samarium oxide nanoparticles prepared by femtosecond laser ablation and fragmentation for nuclear nanomedicine
}

\author{
E. Popova-Kuznetsova ${ }^{a}$, G. Tikhonowski ${ }^{\text {a }}$, A. A. Popova, V. R. Duflot ${ }^{\mathrm{b}}$, S. M. Deyev ${ }^{\mathrm{a}, \mathrm{c}}$, S. M. \\ Klimentov $^{\mathrm{a}}$, I. N. Zavestovskaya ${ }^{\mathrm{a}, \mathrm{d}}$, P. N. Prasad ${ }^{\mathrm{a}, \mathrm{e}}$ and A. V. Kabashin ${ }^{* a, f}$
}

${ }^{\text {a }}$ Bionanophotonic Lab., Institute of Engineering Physics for Biomedicine (PhysBio), National Nuclear Research University MEPHI, Moscow 115409, Russia; ${ }^{b}$ Karpov Institute of Physical Chemistry, NIFKhI, Obninsk 249033, Kaluga region, Russia; ${ }^{\mathrm{c}}$ Shemyakin-Ovchinnikov Institute of Bioorganic Chemistry, Russian Academy of Sciences, Moscow 117997, Russia; ${ }^{d}$ Lebedev Physical

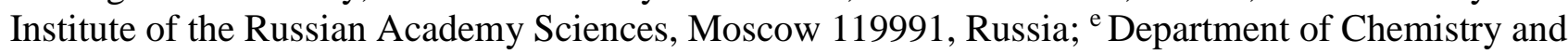
Institute for Lasers, Photonics, and Biophotonics, University at Buffalo, The State University of New York, Buffalo, NY 14260, USA; ${ }^{\mathrm{f}}$ LP3, Aix Marseille University, CNRS, 13288 Marseille, France.

\begin{abstract}
Nanotechnology promises a major improvement of efficacy of nuclear medicine by targeted delivery of radioactive agents to tumors, but this approach still needs novel efficient nanoformulations to maximize diagnostic and therapeutic functions. Here, we present a two-step method of laser ablation and fragmentation in water to produce non-radioactive ${ }^{152} \mathrm{Sm}$-enriched samarium oxide nanoparticles (Sm NPs), which can be converted to radioactive form of ${ }^{153} \mathrm{Sm}$ beta-emitters by neutron capture reaction. We found that laser ablation in deionized water leads to the formation of NPs having diverse morphology and broad size dispersion. To improve size characteristics of formed NPs, we applied additional femtosecond laser fragmentation step, which made possible a good control of mean NPs size under a drastic narrowing of size dispersion, and the spherical shape of formed NPs. Obtained colloidal solutions of Sm NPs were stable for several weeks after the synthesis. The formed NPs present a very promising object for nuclear nanomedicine.
\end{abstract}

Keywords: Sm nanoparticles, femtosecond laser ablation and fragmentation in water, nuclear nanomedicine

\section{INTRODUCTION}

Due to particular physicochemical properties Samarium $(\mathrm{Sm})$ can be used in many areas, including the development of strong magnets [1], control rods of nuclear reactors [2], efficient catalysts [3,4], and agents for biomedicine [5-7]. Nuclear medicine is one of the most perspective domains for $\mathrm{Sm}$ application. ${ }^{152} \mathrm{Sm}$ isotope can captures neutrons by a nuclear reaction, ${ }^{152} \mathrm{Sm}(\mathrm{n}, \gamma)-{ }^{153} \mathrm{Sm}$, to produce the short-lived samarium-based radio isotope ${ }^{153} \mathrm{Sm}$ (half-life is $46.3 \mathrm{hours}$ ), which is known as one of most promising beta emitters for the treatment of malignant tumors, including lung, prostate and breast cancers $[6,7]$.

Sm nanoparticles (NPs) are of particular importance, as they can offer a series of additional advantages, including a large surface area for catalysis [4] and other attractive properties for biomedical applications [8]. Nanoformulations of ${ }^{152} \mathrm{Sm}-$ enriched samarium compounds are of great value for advancing nuclear nanomedicine as it can provide a high local concentration of the radioisotope. Prospects of Sm-based nanoformulations in this diverse range of applications critically depend on the surface conditioning and purity of nanomaterials, but currently-existing routes for the synthesis of Sm nanostructures do not always meet these requirements. Indeed, chemical methods for the preparation of Sm nanoparticles (NPs) [4,9] typically involve hazardous precursors, which could cause residual contamination leading to toxicity issues. Alternative synthesis techniques based on cluster beam deposition [10] and mechanical milling [11] are capable of

*kabashin@1p3.univ-mrs.fr; phone (+33) 491829383 
producing NPs in the dry state, but their subsequent dispersion and stabilization in solutions is problematic due to high surface energy of nanomaterials. Therefore, a facile and scalable technique for the production of Sm-based NPs is still required. Making possible fast production of bare (uncovered) NPs in colloidal state with almost any composition, pulsed laser ablation in liquids [12-17] (PLAL) provides one of best alternatives to satisfy the above-stated demands. As an example, we demonstrated that the technique of femtosecond (fs) laser ablation in liquids can be used for the fabrication of a variety of ultrapure, biologically-friendly nanomaterials, including gold NPs [16,18-22], titanium nitride (TiN) NPs [23], silicon NPs [24-27] and organic polymer NPs [28]. In many cases, such nanoparticles can provide superior properties for catalytic [20], energy and biomedical [29,30] applications, compared to nanomaterials synthesized by conventional chemical methods.

We recently reported a two-step method of fs laser ablation and fragmentation in water for synthesis of pure spherical and size-tunable $(7-70 \mathrm{~nm}){ }^{152} \mathrm{Sm}$-enriched samarium oxide NPs looks promising for nuclear nanomedicine tasks after activation in a nuclear reactor and appropriate biofunctionalization to minimize immune response and target tumors [31]. In this work we present details of structural characterization of the synthesized Sm NPs and results of their long-term storage at ambient conditions.

\section{EXPERIMENTAL METHODS}

We used samarium oxide micropowder enriched with ${ }^{152} \mathrm{Sm}$ isotope (97.78-98.70\%, purity 99.80\%) purchased from Elektrokhimpribor Combine (Lesnoy, Sverdlovsk Region, Russia). The average grain size of the initial micro powder was $0.5-2 \mu \mathrm{m}$. The micropowder was pressed into a cylindrical pellet ( $5 \mathrm{~mm}$ diameter and $150 \mu \mathrm{m}$ thickness), which was then glued to a silicon substrate using an epoxy glue to form a target.

Sm NPs were prepared by two-step method of fs laser ablation and fragmentation in deionized water under ambient conditions, using radiation from a $\mathrm{Yb}: \mathrm{KGW}$ laser (1030 nm wavelength, $270 \mathrm{fs}$ pulse duration, up to $400 \mu \mathrm{J}$ pulse energy, 1-100 kHz repetition rate, TETA 10 model, Avesta, Moscow, Russia). Schematics of the experimental setup for laser ablation and fragmentation in liquid is shown in Fig. 1. In our tests, $3 \mathrm{~mm}$ laser beam was focused by a $75 \mathrm{~mm}$ lens on the surface of the target in the case of laser ablation. For laser fragmentation, the target was removed and preliminarily formed NPs were subjected to laser irradiation from the same laser.

(a)

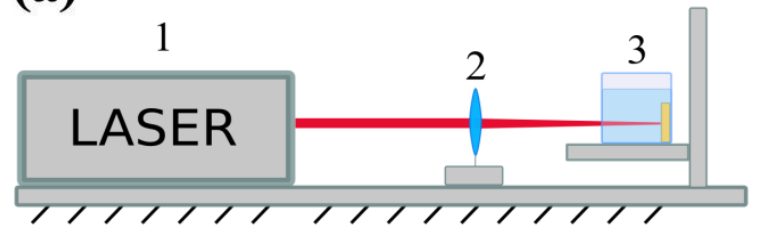

(b)

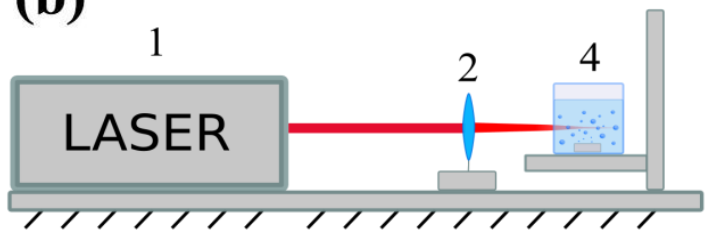

Figure 1. Scheme of the experiment setup for laser ablation (a) and fragmentation (b) in liquids.

1 - laser; 2 - lens; 3 - laser ablation chamber; 4 - laser fragmentation chamber.

For the first step of the laser ablation the Sm oxide target was fixed vertically on the wall of a BK-7 glass vessel filled with $14 \mathrm{~mL}$ of ultrapure water $\left(18.2 \mathrm{M} \Omega \mathrm{cm}\right.$ at $\left.25^{\circ} \mathrm{C}\right)$. The ablation vessel was mounted on a platform, which was continuously scanned over a $2 \times 2 \mathrm{~mm}$ area with the $5 \mathrm{~mm} / \mathrm{s}$ speed in order to avoid ablation from the same area. Ablation was performed with different laser pulse energies ranging from 10 up to $100 \mu \mathrm{J}$. The duration of each experiment was $1 \mathrm{~h}$.

To achieve additional control of NPs size, we applied the second step of fs laser fragmentation (Fig. 1b). Here, we used Sm NPs colloid solution obtained after the laser ablation step. The same optical scheme from the laser ablation setup was used, but the laser beam was focused into the solution $1 \mathrm{~cm}$ behind the entrance glass rather than on the target surface. The solution was continuously homogenized by a magnetic stirrer during the fragmentation process.

A scanning transmission electron microscopy (STEM) system (MAIA 3, Tescan, Czech Republic) operating at 0.1-30 kV coupled with an EDS detector (X-act, Oxford Instruments, High Wycombe, UK) was used to characterize morphology, structure, size and composition of the synthesized NPs. Samples for electron microscopy were prepared by dropping $1 \mu \mathrm{L}$ 
of the NPs solution onto a carbon-coated copper grid (for transmission electron microscopy (TEM) imaging) or a cleaned silicon substrate (for scanning electron microscopy (SEM) imaging) and with subsequent drying at ambient conditions. $\zeta$ - potential of NPs in water was measured using a Zetasizer ZS instrument (Malvern Instruments, Orsay, Paris, France). MC 122 Spectrophotometer (SOL instruments Ltd., Minsk, Republic of Belarus) was used to measure extinction spectra of Sm NPs colloidal solutions.

\section{RESULTS AND DISCUSSION}

Bare Sm NPs colloidal solutions were prepared by two-step fs laser ablation and fragmentation in deionized water, similar to the procedure reported in our previous works $[18,20]$. The solutions were almost completely transparent, with a slight whitish coloration and concentration in the range from 30 to $50 \mu \mathrm{g} / \mathrm{mL}$ (depending on the laser pulse energy). Fig. 2 shows a typical TEM images of Sm NPs obtained after the first step of laser ablation. As one can see, NPs were very diverse both in form and size. There are four fractions of NPs can be distinguished: (i) Relatively large randomly shaped particles with sizes from $100 \mathrm{~nm}$ up to $1 \mu \mathrm{m}$, (ii) thread-like structures with 20-40 nm thickness and 200-500 nm length, (iii) amorphous particles with sizes up to $100 \mathrm{~nm}$ and, (iv) spherical NPs with sizes from 10 to $100 \mathrm{~nm}$.

(a)

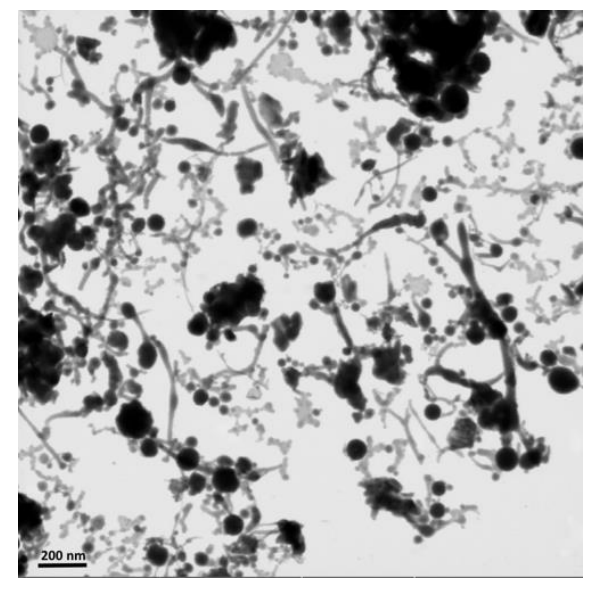

(b)

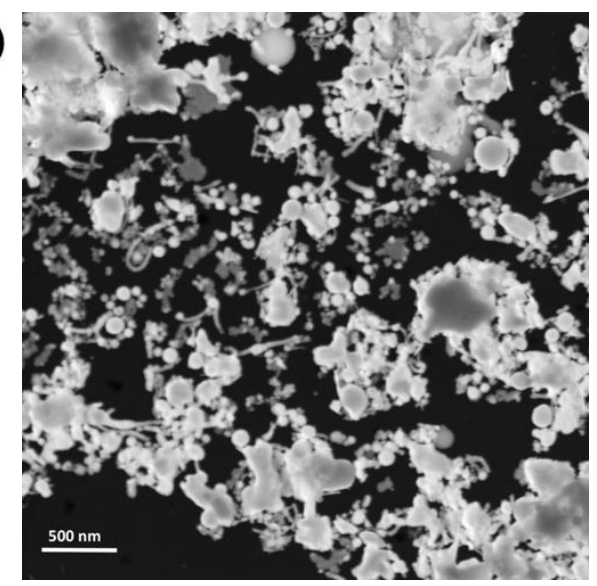

Figure 2. Typical TEM images of Sm NPs obtained by laser ablation of Sm oxide target with (a) $20 \mu \mathrm{J}$ and (b) $100 \mu \mathrm{J}$ pulse energy.

First three fractions did not demonstrate any noticeable dependence of their morphological properties on the pulse energy. We suppose that this observation can be explained by a non-laser-ablative origin of such NPs. Indeed, the size of large randomly shaped particles $(100 \mathrm{~nm}-1 \mu \mathrm{m})$ was very similar to the initial micro powder grains, and therefore they could be produced by mechanical detachment from the target during the ablation process. The problem of mixing of educt particles from a pressed powder-based target with truly laser ablated particles has been reported by many authors [32,33]. The reason for such a mechanical ablation is collapse of a cavitation bubble, which emerges at the liquid-target boundary, promptly after a laser pulse due to fast liquid heating by the ablated material. In the case of fs ablation, it is possible to completely suppress the cavitation bubble and the related mechanical mechanism of ablation, by the decrease of laser energy [16]; however, it leads to very low ablation productivity. At the same time, the formation of thread-like and amorphous particles (fractions (ii) and (iii)) could be explained by thermal and oxidative mechanisms accordingly. In contrast, spherical NPs tended to increase their size, with an increase of the laser pulse energy. The mean size of the spherical NPs increased from $20 \mathrm{~nm}$ to $70 \mathrm{~nm}$, when the laser ablation energy was increased from 10 to $100 \mu \mathrm{J}$. This observation is consistent with the dependence of the NPs size on pulse energy during laser ablation for other materials.

Therefore, one-step laser ablation can not provide good control of Sm NPs size characteristics, as formed NPs have a large mean size and are size- and shape-dispersed. Such characteristics are hardly consistent with projected applications. To homogenize size distributions, we applied the second step of laser fragmentation in liquids (LFL), which was developed in our earlier works to reduce the size of Au and TiN NPs [18,23]. Fig. 3 presents the typical TEM image of Sm NPs obtained after this additional laser treatment. As one can see, two-step laser ablation and fragmentation in liquid allows to produce spherical NPs with narrow size distribution. Moreover, the size of formed NPs can be controlled by varying the 
laser fragmentation pulse energy. For instance, prolonged LFL with $50 \mu \mathrm{J}$ pulse energy led to log-normal size distribution of Sm oxide NPs with $20 \mathrm{~nm}$ mean diameter and $10 \mathrm{~nm}$ FWHM width. While LFL with $100 \mu \mathrm{J}$ pulse energy resulted in NPs with $7 \mathrm{~nm}$ mean diameter. This result is consistent with our previous results on fs laser fragmentation of Au NPs [18]. Here, under certain conditions, we could also observe the decrease of NPs size under the increase of laser fluence.

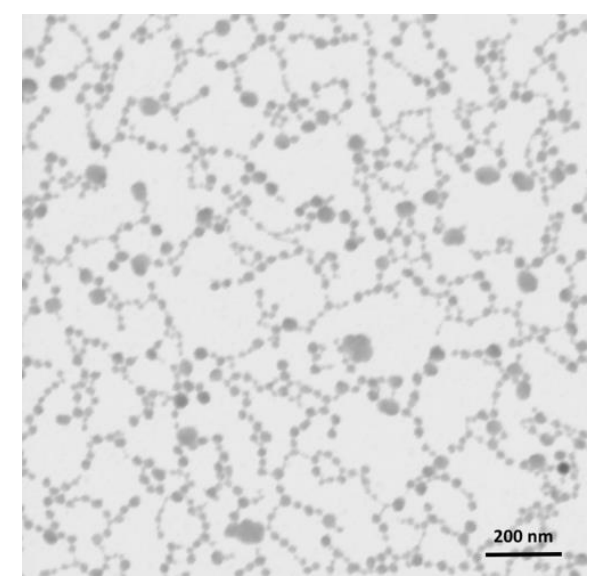

Figure 3. Typical TEM image of Sm NPs obtained after laser fragmentation step.

We observed some sedimentation of particles during the first 24 hours after the laser ablative preparation of solutions. This sedimentation can be attributed to precipitation of the large size mechanically ablated particles, as discussed previously. After that, the remaining solutions were stable and did not show any traces of precipitation during their storage under room conditions for several weeks. Such a good colloidal stability of bare laser-synthesized colloids is dictated by electrical charging of NPs during the ablation process and related electrostatic stabilization. Indeed, according to our $\zeta$ - potential measurements, the surface potential of the laser ablated Sm oxide NPs was $+20 \mathrm{mV}$ which coincides with the stability threshold for colloidal solutions. It is important that after the fs laser fragmentation step, colloidal solutions did not show any sign of precipitation, which was obviously due to homogenation of NPs sizes.

However, we have found that ten months after the two-step laser synthesis the obtained Sm NPs in colloidal solution began to coalesce and form agglomerates. We applied an ultrasonication procedure to break up agglomerates and thus return colloidal solution to initial form. But even one-hour ultrasonic treatment did not show any significant results as indicated by DLS size measurement (Fig. 4, circles). At the same time the method of LFL allowed to slightly decrease the mean size of NPs in time-depended manner (Fig. 4, diamonds). Note, that even long-term fragmentation left significant amount of unfragmented aggregates.

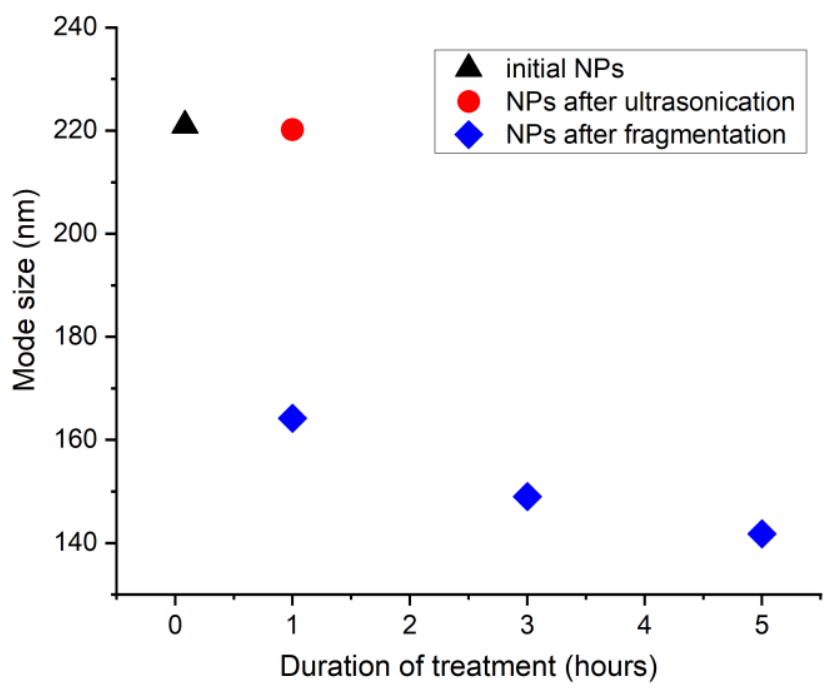

Figure 4. DLS size measurement. 
Extinction spectra of Sm NPs colloidal solutions (Fig. 5) were consistent with DLS measurements. Indeed, LFL of the Sm NPs colloid led to homogeneous decrease of extinction profile which corresponds to decrease of NPs size because scattering scales with the size as $r^{6}$, where $r-$ is a size of NPs.

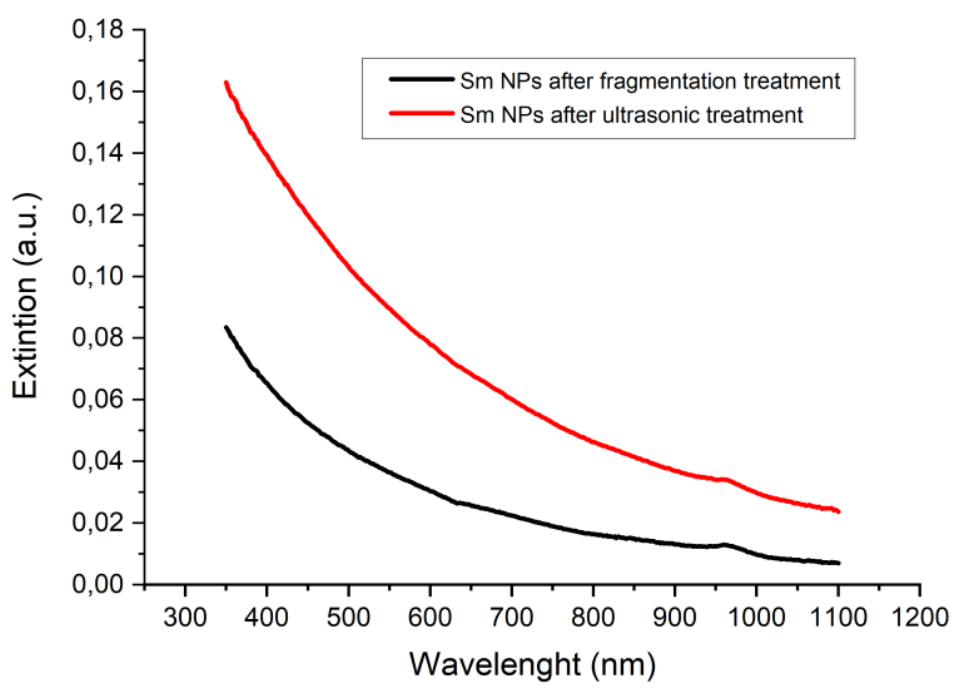

Figure 5. Extinction spectra of Sm NPs colloidal solutions

\section{CONCLUSIONS}

Two-step method of laser ablation and fragmentation in liquid was used to produce aqueous colloidal solutions of ${ }^{152} \mathrm{Sm}$ oxide NPs. We have found that after the first step of laser ablation in deionized water the morphology of obtained nanoparticles was very diverse both in size and in shape. To produce spherical ${ }^{152} \mathrm{Sm}$ nanoparticles with narrow size distribution the additional step of laser fragmentation in liquid was used. The variation of laser fragmentation pulse energy allows to control the mean size of synthesized nanoparticles. Prolonged storage of Sm NPs for 10 months led to irreversible aggregation. The aggregates can not be destroyed by ultrasonication, but can be partly reduced by laser fragmentation step. The formed NPs promise exciting perspectives for its application in nuclear nanomedicine.

\section{ACKNOWLEDGEMENTS}

The authors acknowledge the contribution of the Russian Science Foundation (Project 19-72-30012) for the fabrication of samples.

\section{REFERENCES}

[1] Ojima, T., Tomizawa, S., Yoneyama, T., Hori, T., "Magnetic properties of a new type of rare-earth cobalt magnets Sm2(Co, Cu, Fe, M)17," IEEE Trans. Magn, 13, 1317-1319 (1977). AVK: Toma nuzhno v bold, nuzhno takzhe proverit' upper and lower cases v himicheskih formulah

[2] Lamarsh, J. R., [Introduction to nuclear reactor theory], 1st editio., Addison-Wesley Publishing Company, New York (1966).

[3] Kagan, H.B, “Twenty-five years of organic chemistry with diiodosamarium: an overview," Tetrahedron, 59 (52), 10351-10372 (2003).

[4] Zheng, X., Li, X., Peng, H., Wen, J., “Ag-decorated core-shell Sm2O3@TiO2 nanocomposites with enhanced 
Resche, I., Chatal, J.-F., Pecking, A., Ell, P., Duchesne, G., Rubens, R., Fogelman, I., Houston, S., Fauser, A., Fischer, M., et Wilkins, D., "A dose-controlled study of 153Sm-Ethylenediaminetetramethylenephosphonate (EDTMP) in the treatment of patients with painful bone metastase,” Eur. J. Cancer, 33 (10), 1583-1591 (1997).

[6] Alberts, A.S.; Smit, B.J.; Louw, W.K.A.; van Rensburg, A.J.; van Beek, A.; Kritzinger, V.; Nel, J.S. Dose response relationship and multiple dose efficacy and toxicity of samarium-153-EDTMP in metastatic cancer to bone. Radiother. Oncol. 1997, 43, 175-179.

[7] Serafini, A. N., Houston, S. J., Resche, I., Quick, D. P., Grund, F. M., Ell, P. J., Bertrand, A., Ahmann, F. R., Orihuela, E., Reid, R. H., Lerski, R. A., Collier, B. D., McKillop, J. H., Purnell, G. L., Pecking, A. P., Thomas, F. D., and Harrison, K. A., "Palliation of pain associated with metastatic bone cancer using samarium-153 lexidronam: a double-blind placebo-controlled clinical trial," J. Clin. Oncol., 16, 1574-1581 (1998).

[8] Ascencio, J. A., Rincon, A. C., Canizal, G., "Synthesis and Theoretical Analysis of Samarium Nanoparticles: Perspectives in Nuclear Medicine.," J. Phys. Chem. B., 109, 8806-8812 (2005).

[9] Shiri, M. H., Ehsani, A., Khales, J. M., "Electrochemical synthesis of Sm2O3 nanoparticles: Application in conductive polymer composite films for supercapacitors," J. Colloid Interface Sci., 505, 940-946 (2017).

[10] Akdogan, O., Li, W., Hadjipanayis, G. C., Sellmyer, D. J., "Synthesis of single-crystal Sm-Co nanoparticles by cluster beam deposition," J. Nanoparticle Res., 13, 7005-7012 (2011).

[11] Mandiwana, V., Kalombo, L., Venter, K., Sathekge, M., Grobler, A., Zeevaart, J. R., "Samarium oxide as a radiotracer to evaluate the in vivo biodistribution of PLGA nanoparticles," J. Nanoparticle Res., 17, 375 (2015).

[12] Fojtik, A., Henglein, A., "Laser Ablation of Films and Suspended Particles in Solvent-Formation of Cluster and Colloid Solutions,” Ber. Bunsenges. Phys. Chem., 97, 252 (1993).

[13] Sibbald, M. S., Chumanov, G., Cotton, T. M., "Reduction of Cytochrome c by Halide-Modified, Laser-Ablated Silver Colloids,” J. Phys. Chem., 100 (11), 4672-4678 (1996).

[14] Mafuné, F., Kohno, J., Takeda, Y., Kondow, T., Sawabe, H., "Formation of Gold Nanoparticles by Laser Ablation in Aqueous Solution of Surfactant," J. Phys. Chem. B, 105 (22), 5114-5120 (2001).

[15] Dolgaev S. I., Sinakin A.V., Vornov V. V., Shafeev G. A., "Bozon-Verduaz F Nanoparticles Produced by Laser Ablation of Solids in Liquid Environment,” Appl. Surf. Sci., 186 (1), 546-551 (2002).

[16] Kabashin, A. V., Meunier, M., "Synthesis of Colloidal Nanoparticles during Femtosecond Laser Ablation of Gold in Water," J. Appl. Phys., 94 (12), 7941 (2003).

[17] Kabashin, A. V., Meunier, M., "Femtosecond Laser Ablation in Aqueous Solutions: A Novel Method to Synthesize Non-Toxic Metal Colloids with Controllable Size,” J. Phys. Conf. Ser., 59, 354-359 (2007).

[18] Maximova, K., Aristov, A., Sentis, M., Kabashin, A. V., "Size-controllable synthesis of bare gold nanoparticles by femtosecond laser fragmentation in water," Nanotechnology, 26, 065601 (2015).

[19] Correard, F., Maximova, K., Estève, M.-A., Villard, C., Roy, M., Al-Kattan, A., Sentis, M., Gingras, M., Kabashin, A. V., Braguer, D., "Gold Nanoparticles Prepared by Laser Ablation in Aqueous Biocompatible Solutions: Assessment of Safety and Biological Identity for Nanomedicine Applications,” Int. J. Nanomedicine, 9, 5415-5430 (2014).

[20] Hebié, S., Holade, Y., Maximova, K., Sentis, M., Delaporte, P., Kokoh, K.B., Napporn, T.W., Kabashin, A.V., "Advanced Electrocatalysts on the Basis of Bare Au Nanomaterials for Biofuel Cell Applications," ACS Catal., 5, 6489-6496 (2015).

[21] Kögler, M., Ryabchikov, Y. V., Uusitalo, S., Popov, A., Popov, A., Tselikov, G., Välimaa, A.-L., Al-Kattan, A., Hiltunen, J., Laitinen, R., Neubauer, P., Meglinski, I., Kabashin, A.V., "Bare laser-synthesized Au-based nanoparticles as nondisturbing surface-enhanced Raman scattering probes for bacteria identification," J. Biophotonics, 11 (7), e201700225 (2018).

[22] Bailly, A.-L., Correard, F., Popov, A., Tselikov, G., Chaspoul, F., Appay, R., Al-Kattan, A., Kabashin, A. V., Braguer, D., Esteve, M.-A., "In vivo evaluation of safety, biodistribution and pharmacokinetics of lasersynthesized gold nanoparticles," Sci. Rep., 9 (1), 12890 (2019).

[23] Popov, A. A., Tselikov, G., Dumas, N., Berard, C., Metwally, K., Jones, N., Al-Kattan, A., Larrat, B., Braguer, D., Mensah, S., Da Silva, A., Estève, M.-A., Kabashin, A. V., "Laser- synthesized TiN nanoparticles as promising plasmonic alternative for biomedical applications," Sci. Rep., 9 (1), 1194 (2019).

[24] Baati, T., Al-kattan, A., Esteve, M., Njim, L., Ryabchikov, Y., Chaspoul, F., Hammami, M., Sentis, M., Kabashin, A. V., Braguer, D., "Ultrapure Laser-Synthesized Si-Based Nanomaterials for Biomedical Applications: In Vivo Assessment of Safety and Biodistribution," Sci. Rep., 6, 1-13 (2016).

[25] Al-Kattan, A., Ryabchikov, Y. V., Baati, T., Chirvony, V., Sánchez-Royo, J. F., Sentis, M., Braguer, D., 
Timoshenko, V. Y., Estève, M.-A., Kabashin, A. V., "Ultrapure Laser-Synthesized Si Nanoparticles with Variable Oxidation States for Biomedical Applications," J. Mater. Chem. B, 4, 7852-7858 (2016).

[26] Petriev, V. M., Tischenko, V. K., Mikhailovskaya, A. A., Popov, A. A., Tselikov, G., Zelepukin, I., Deyev, S. M., Kaprin, A. D., Ivanov, S., Timoshenko, V. Y., Prasad, P. N., Zavestovskaya, I. N., Kabashin, A. V., "Nuclear Nanomedicine Using Si Nanoparticles as Safe and Effective Carriers of 188Re Radionuclide for Cancer Therapy," Sci. Rep., 9 (1), 2017 (2019).

[27] Kharin, A. Y., Lysenko, V. V., Rogov, A., Ryabchikov, Y. V., Geloen, A., Tishchenko, I., Marty, O., Sennikov, P. G., Kornev, R. A., Zavestovskaya, I. N., Kabashin, A. V., Timoshenko, V. Y., "Bi-Modal Nonlinear Optical Contrast from Si Nanoparticles for Cancer Theranostics,” Adv. Opt. Mater., 7, 1801728 (2019).

[28] Lim, C.-K., Popov, A. A., Tselikov, G., Heo, J., Pliss, A., Kim, S., Kabashin, A. V., Prasad, P. N. “Organic Solvent and Surfactant Free Fluorescent Organic Nanoparticles by Laser Ablation of Aggregation-Induced Enhanced Emission Dyes," Adv. Opt. Mater., 6, 1800164 (2018).

[29] Kabashin, A. V., Timoshenko, V. Y. "What Theranostic Applications Could Ultrapure Laser-Synthesized Si Nanoparticles Have in Cancer?," Nanomedicine, 11, 2247-2250 (2016).

[30] Kabashin, A. V., Singh, A., Swihart, M., Zavestovskaya, I. N., Prasad, P. N., "Laser Processed Nanosilicon: A Multifunctional Nanomaterial for Energy and Health Care," ACS Nano., 13, 9841-9867 (2019).

[31] Popova-Kuznetsova, E., Tikhonowski, G., Popov, A.A., Duflot, V., Deyev, S., Klimentov, S., Zavestovskaya, I., Prasad, P.N., Kabashin, A.V., "Laser-Ablative Synthesis of Isotope-Enriched Samarium Oxide Nanoparticles for Nuclear Nanomedicine," Nanomaterials, 10, 69 (2020).

[32] Wang, H., Odawara, O., Wada, H., "Facile and chemically pure preparation of YVO4:Eu3+ colloid with novel nanostructure via laser ablation in water," Sci. Rep., 6, 20507 (2016).

[33] Schmitz, T., Wiedwald, U., Dubs, C., Gökce, B., "Ultrasmall yttrium iron garnet nanoparticles with high coercivity at low temperature synthesized by laser ablation and fragmentation of pressed powders," ChemPhysChem, 18, 1125-1132 (2017). 